\title{
Performance levels of four Latin American laboratories for the serodiagnosis of Chagas disease in Mexican sera samples
}

\author{
Alejandro O Luquetti' ${ }^{1}$, Bertha Espinoza ${ }^{2}$, Ignacio Martínez ${ }^{2}$, Nidia Hernández-Becerril ${ }^{3}$, \\ Carlos Ponce ${ }^{4}$, Elisa Ponce ${ }^{4}$, Pedro A Reyes ${ }^{3}$, Oscar Hernández ${ }^{5}$, Ruth López ${ }^{5}$, Victor Monteón ${ }^{3,5} /+$
}

${ }^{1}$ Instituto de Patología Tropical e Saúde Pública, Universidade Federal de Goiás, Goiania, Brasil ²Departamento de Inmunología, Instituto Investigaciones Biomédicas, Universidad Nacional Autónoma de México, México DF, México ${ }^{3}$ nnstituto Nacional Cardiología I. Chávez, México DF, México ${ }^{4}$ Laboratorio de Referencia para Enfermedad de Chagas y Leishmaniasis, Secretaria de la Salud, Tegucigalpa, Honduras ${ }^{5}$ Centro Investigación Enfermedades Tropicales, Universidad Autónoma Campeche, Av. Patricio Trueba s/n, 24090 Campeche, México

In nearly all of the previous multicentre studies evaluating serological tests for Trypanosoma cruzi infection, sera samples from Central or South American countries have been used preferentially. In this work we compared the reliability of the serological tests using Mexican sera samples that were evaluated in four independent laboratories. This included a reference laboratory in Brazil and three participant laboratories, including one in Central America and two in Mexico. The kappa index between Brazilian and Honduran laboratories reached 1.0 and the index for the Mexican laboratories reached 0.94. Another finding of this study was that the source of antigen did not affect the performance of the serological tests.

Key words: Trypanosoma cruzi - Chagas disease - serological tests - blood donors - Mexican strains

American trypanosomiasis, also commonly known as Chagas disease, is caused by the protozoan flagellate Trypanosoma cruzi. Diagnosis of the chronic phase is typically based on the detection of $\operatorname{IgG}$ antibodies in the sera of patients. The serological tests currently in use are indirect immunofluorescence (IIF), indirect hemagglutination (IHA) and enzyme-linked immunosorbent assay (ELISA). They regularly use crude antigenic T. cruzi preparations or semipurified fractions and more recently these tests have used recombinant antigens (Oeleman et al. 1998, Luquetti et al. 2003, Umezawa et al. 2004, Cooley et al. 2008). Although many screening methods and sources of antigens have been evaluated, sensitivity and specificity levels have seldom reached 100\%. It has been suggested that variability among $T$. cruzi isolates in conjunction with immunogenetic features of the human host and environmental factors could affect the performance of serological tests (Umezawa et al. 1999, Luquetti et al. 2003).

T. cruzi consists of a pool of sub-populations that presents high heterogeneity in both biological parameters and genetic characteristics (Souto et al. 1996, Espinoza et al. 1998, Briones et al. 1999).

As a whole, serum samples from infected patients react better to whole parasite extracts than recombinant antigens, which is likely due to the presence of a large number of antigenic determinants. Nevertheless, some variation of ELISA absorbance values in serum samples from different countries has been observed (Umezawa et al. 1999). Furthermore, higher titers of anti T. cruzi

Financial support: DGAPA (IN226402), UNAM (BE), PROMEP/ 103.5/04/833 (VM)

+ Corresponding author: victormonteon@yahoo.com.mx

Received 19 January 2009

Accepted 26 June 2009 antibodies have been detected in individuals residing in high endemic regions for $T$. cruzi infection when compared against infected individuals living in low endemic areas (Borges-Pereira \& Coura 1986, Sosa-Jurado et al. 2003). The same observations hold true for those symptomatic with chronic chagasic cardiopathy when compared against those who are asymptomatic for chronic chagasic cardiopathy (Nava et al. 2001).

In nearly all of the previously conducted multicentric studies that evaluated serological tests of T.cruzi infection, only sera samples from Central or South American countries have been evaluated. The aim of this work was to compare the reliability of serological tests using Mexican blood samples and Mexican T. cruzi isolates. We then wanted to compare these results to those from several South and Central American laboratories.

México is the most northern country in the American continents in which T. cruzi infections are endemic, with an estimated infected population of approximately $1,768,376$. Within the infected population, acute, cardiac and symptomless human cases have been described (Mendoza et al. 1995, Monteon-Padilla et al. 1999, Mazariego-Arana et al. 2001, Ramsay et al. 2003). The predominate T. cruzi group identified in Mexican chagasic patients has been lineage I (Bosseno et al. 2002, Ruíz-Sánchez et al. 2005). The samples used in this current study were collected at the Instituto Nacional de Cardiología I. Chavéz, which is located in México City. A panel of 98 serum samples consisting of seropositive and seronegative blood donor sera was used. This included a group of 15 sera samples from chronic chagasic cardiopathy patients (CCC) who underwent a clinical evaluation (ECG, chest X-ray, ECO tests) and also had two serologic positive tests carried out at the Instituto Nacional Cardiología I. Chavéz. In addition, five of the sera samples were from non-chagasic cardiopathy patients and used as negative controls. Samples 
were stored in $50 \%$ glycerol for serum reactivity preservation and were sent to the participating laboratories in Brazil [Instituto de Patologia Tropical e Saúde Pública, Universidade Federal de Goiás (UFG), Goiania], Honduras [Laboratorio de Referencia para Enfermedad de Chagas y Leishmaniasis, Secretaria de la Salud (SS), Tegucigalpa] and México [Departamento de Inmunología, Instituto Investigaciones Biomédicas (IIB), Universidad Nacional Autónoma de México, México DF]. A fourth set of samples remained at the Instituto Nacional de Cardiología I. Chávez, in México City.

All blood donors were clinically evaluated by the blood banking service before their acceptance as candidates. Each participating laboratory applied their individual routine serologic techniques to establish $T$. cruzi infection.

The Brazilian laboratory (UFG) was considered to be the reference centre for our study. In this institution, the IIF was performed using formaldehyde-treated epimastigote forms of T. cruzi (Y strain). Results were considered to be positive when a dilution of $1 / 40$ or above showed positivity (Umezawa et al. 1999). An "in house" ELISA was performed using a crude extract of $Y$ strain epimastigotes and the results were expressed as an index. The index was obtained by dividing the optical density (OD) of the sample by the OD of the plate cut-off. $A n$ index value that was equal to or greater than 1.2 was considered to be positive. For IHA, the results were expressed as the reciprocal of titer dilution. Titers equal to or above 32 were considered to be positive. The detection of anti-T. cruzi antibodies by three different serologic tests was the criterion used to characterise an infected individual. In addition, anti-leishmania IIF serology was used as a complementary test.

In the Honduras laboratory (SS), two commercial ELISA versions were used. This included ELISA using the crude native extract (Wiener Lab) and ELISA using recombinant antigens (Wiener Lab). In both cases, the manufacturer's instructions were followed. A third rapid immunochromatographic screening test (Chembio Diagnostic Systems, Medford, NY, USA) was also used for the detection of anti-T.cruzi antibodies. IIF was performed using formaldehyde-treated epimastigote forms of $T$. cruzi (Y strain) and fluorescein-isothiocyanate sheep anti-human IgG (Fluoline G, Biolab Diagnóstica SA, RJ, Brazil). The results were considered positive when a dilution equal to or above $1 / 40$ was observed.

In the Mexican (IIB) laboratory, two serologic "in house" tests were performed, which were ELISA and western blot. ELISA was performed using a crude extract from the Queretaro Mexican T. cruzi isolate. Each test was carried out in duplicate. Negative and positive sera controls were run for each plate. The ELISA cut-off point was obtained by calculating the OD average of negative controls +2.5 standard deviations. For the western blot, proteins of the total extract (Queretaro isolate) were separated by SDS-PAGE and transferred to nitrocellulose membranes (100 $\mu \mathrm{g}$ of protein each). After an overnight saturation in PBS containing $10 \%$ skimmed milk at $4^{\circ} \mathrm{C}$ with constant shaking, the nitrocellulose membrane was cut into strips and these strips were individually in- cubated for $2 \mathrm{~h}$ at RT in $1 \mathrm{~mL}$ of human serum diluted $1: 500$ in PBS $/ 10 \%$ skimmed milk with constant shaking. Positive and negative control sera were included in each experiment (Sanchez et al. 2001). A positive result was noted when two or more bands were present.

In the Mexican (INC) laboratory, two serologic homemade tests were performed. An IIF assay was carried out as reported (Ramos-Echavarria et al. 1993). To briefly explain, a drop of epimastigote (Ninoa Mexican Strain) suspension was air dried on a slide. Human experimental and control sera were then diluted at 1:32 (cut-off dilution) in PBS and incubated in a humidified chamber for $30 \mathrm{~min}$. If fluorescence of the parasites was observed, the sample was scored as positive. ELISA was then conducted using polystyrene plates (Immunolon II Thermo Labsystems, Franklin, Mass.) coated with 10 $\mu \mathrm{g} / \mathrm{ml}$ of $T$. cruzi protein (Ninoa Mexican strain) extract in an alkaline-buffered solution. Human serum was diluted at 1:200 and anti-human IgG-peroxidase conjugate was used at a 1:15,000 dilution (Zymed Lab, Santa Cruz $\mathrm{Ca}$, USA). The reaction was revealed by the addition of O-phenilen-diamine and read at $490 \mathrm{~nm}$ in an automatic ELISA reader (Biorad, Palo Alto Ca, USA). The cut off value was set by testing the sera from 30 healthy seronegative people, which was then pooled and individually tested. Mean OD ratios obtained between an individual negative sample and the pooled negative sample were analyzed for their distribution. The mean OD ratio of seronegative healthy individuals plus $3 \mathrm{SD}$ was fixed to set the cut off. All healthy individuals had values classified as negative. The determination of anti-leishmania antibodies by IIF was also included in the study as a complementary test.

Using the laboratory values obtained in Brazil as a reference, we estimated the sensitivity, specificity and $\kappa$ index. Positive samples were those with at least two serological positive results, whereas negative samples were either samples with all negative results or two negative results and one positive result.

Despite the fact that Mexican laboratories used $T$. cruzi Mexican isolates that belonged to lineage I (Ninoa and Queretaro), their diagnostic performance and reliability showed acceptable results.

The Kappa index indicated a high proportion of true agreement among the four participating laboratories. For the SS, the index was 1.0, which is an excellent result. Sensitivity, which is the ability of the method to identify true positives, reached levels of $100 \%$. The sensitivity parameter is very important for avoiding false negatives. The specificity levels also reached $100 \%$ as well. Although the SS ranked the highest in all parameters, the results reached in Mexican laboratories were very close and comparable. The sensitivity in both laboratories reached $100 \%$ and specificities were found to be between $91-98 \%$ with Kappa indices between 0.93-0.98 (Table).

Even though the participating laboratories applied their own techniques and antigens, high concordance, specificities and sensitivities were observed when examining the Mexican samples of both infected and uninfected individuals. 
TABLE

Laboratory performance in the serodiagnosis of Trypanosoma cruzi infection

\begin{tabular}{lcccc}
\hline & Brazil $^{a}$ & Honduras $^{b}$ & Mexico $^{c}$ & Mexico $^{d}$ \\
\hline True positive $^{e}(\mathrm{n})$ & 40 & 40 & 43 & 43 \\
True negative $^{f}(\mathrm{n})$ & 58 & 58 & 55 & 55 \\
Sensitivity (\%) & & 100 & 100 & 100 \\
Specificity (\%) & & 100 & 94.8 & 94.8 \\
PPV $^{3}(\%)$ & & 100 & 93 & 93 \\
NPP $^{4}(\%)$ & 100 & 100 & 100 \\
Kappa index & & 1.0 & 0.94 & 0.94 \\
\hline
\end{tabular}

$a$ : Instituto de Patologia Tropical e Saúde Pública, Universidade Federal de Goiás, Goiânia; $b$ : Laboratorio de Referencia para Enfermedad de Chagas y Leishmaniasis, Secretaria de la Salud, Tegucigalpa; $c$ : Departamento de Inmunología, Instituto Investigaciones Biomédicas, Universidad Nacional Autónoma de México, México DF; $d$ : Instituto Nacional de Cardiología I. Chávez, México DF; $e$ : at least two concordant positive results; $f$ : all tests negative; NPP: negative predictive value; PPV: positive predictive value.

A remarkable finding was the excellent agreement with the CCC samples, given that the four laboratories recognised all of them as positive. However, when we compared the results of blood donor samples the concordance was lower for the Mexican laboratories. On the other hand, in Brazil (UFG), 14 leishmaniasis reactive samples in the blood donor group were detected by IIF, eight of which reacted to both leishmania and T. cruzi antigens. We believe that the cross-reactivity is due to membrane antigens, because the sera were negative in both the ELISA and IHA tests. The remaining six positive anti-leishmania samples reacted solely to leishmania antigens. On the other hand, in Mexico (INC), only six samples out of the 14 initially identified as positive in Brazil (UFG) tested positive. Among these, five reacted solely to leishmania antigens. This finding may suggest that the IIF assay may be more cross-reactive with antigens between the two species when compared against the ELISA or IHA assays.

Another interesting finding was that the recombinant antigens used in Honduras (SS) showed identical performances to the crude extract that was used (Wiener Lab ELISA). In addition, similar results were obtained with the rapid immunochromatographic test (Chembio Diagnostic Systems, Medford, NY, USA), suggesting its use as a reliable testing method.

To sum up, the data indicate that humoral immune responses of Mexican chagasic infected individuals are able to recognise antigens from either Mexican or Brazilian parasite strains, independent of which T. cruzi lineage they belong to.

In conclusion, our data strongly support that serological tests in Mexican laboratories are acceptable and that both the geographical origin of the serum samples and the use of T. cruzi I as a source of antigens do not affect the performance of serological assays.

\section{ACKNOWLEDGEMENTS}

To Silvia Monteón, for English correction of the manuscript.

\section{REFERENCES}

Borges-Pereira J, Coura JR 1986. Morbidade da doença de Chagas. Estudo seccional em uma área endệmica, Virgen da Lapa, Minas Gerais. Rev Soc Bras Med Trop 19: 139-148.

Bosseno MF, Barnabé C, Magallón-Gastelum E, Lozano-Kasten F, Ramsay J, Espinoza B, Breniere SF 2002. Predominance of Trypanosoma cruzi I lineage in Mexico. J Clin Microbiol 40: 627-632.

Briones MR, Souto RP, Stolf BS, Zingales B 1999. The evolution of two Trypanosoma cruzi subgroups inferred from rRNA genes can be correlated with interchange of American mammalian faunas in the Cenozoic and has implicated to pathogenicity and host specificity. Mol Biochem Parasitol 104: 219-232.

Cooley G, Etheridge D, Boehlke B, Weatherly B, Minning T, Haney M, Postan M, Laucella S, Tarleton R 2008. High throughput selection of effective serodiagnostics for Trypanosoma cruzi infection. Plos Neglec Trop Dis 2: 1-12.

Espinoza B, Vera-Cruz JM, Gonzalez H, Ortega E, Hernández R 1998. Genotype and virulence correlation within Mexican stocks isolated from patients. Acta Trop 70: 63-72.

Luquetti AO, Ponce C, Ponce E, Esfandiari J, Schijman A, Revollo S, Anez S, Zingales B, Rangel-Aldao R, Gonzalez A, Levin MJ, Umezawa ES, da Silveira JF 2003. Chagas' disease diagnosis: a multicentric evaluation of Chagas Stat-Pack, a rapid immunochromatographic assay with recombinant proteins of Trypanosoma cruzi. Diag Microbiol Inf Dis 46: 265-271.

Mazariego-Arana M A, Monteón VM, Ballinas-Verdugo M, HernándezBecerril N, Alejandre-Aguilar R, Reyes PA 2001. Seroprevalence of human Trypanosoma cruzi infection in different geographic zones of Chiapas, México. Rev Soc Bras Med Trop 34: 453-458.

Mendoza, JA, Miranda E, Velasco-Castrejón O, Maciel MO 1995. Cardiopatía chagásica crónica. Presentación de 60 casos. Arch Inst Cardiol Mex 65: 546-550.

Monteón-Padilla VM, Hernández-Becerril N, Guzmán-Bracho C, Rosales-Encinas JL, Reyes-López PA 1999. American trypanosomiasis (Chagas' disease) and blood banking in México City. Seroprevalence and its potential transfusional transmission risk. Arch Med Res 30: 393-398.

Nava A, Reyes PA, Monteón VM, Hernandez-Becerril N 2001. IgG subclass reactivity to Trypanosoma cruzi in chronic Chagas'disease. Arch Cardiol Mex 71: 199-205.

Oeleman WM, Teixeira MG, da Costa GV, Borges-Pereira J, de Castro JA, Peralta JM 1998. Evaluation of three comercial enzymelinked immunosorbent assays for diagnosis of Chagas' disease. J Clin Microbiol 36: 2433-2427.

Ramos-Echavarria A, Monteón VM, Reyes PA 1993. Detección de anticuerpos contra Trypanosoma cruzi en donadores de sangre. Salud Publica Mex 35: 56-61.

Ramsey J, Ordoñez R, Tello-López A, Pohls J, Sánchez V, Peterson A 2003. Actualidades sobre la epidemiología de la enfermedad de Chagas en México. In J Ramsey, A Tello, J Pohls, Iniciativa para la vigilancia y el control de la enfermedad de Chagas en la república mexicana, Instituto Salud Pública, México, p. 85-103.

Ruíz-Sánchez R, de León P, Matta V, Reyes PA, Jay D, Monteón VM 2005. Trypanosoma cruzi isolates from Mexican and Guatemalan acute and chronic chagasic cardiopathy patients belong to Trypanosoma cruzi I. Mem Inst Oswaldo Cruz 100: 281-283.

Sánchez B, Monteón V, Reyes PA, Espinoza B 2001. Standardization of micro-enzyme-linked immunusorbent assay (ELISA) and western 
blot for detection of Trypanosoma cruzi antibodies using extracts from Mexican strains as antigen. Arch Med Res 32: 382-388.

Sosa-Jurado F, Mazariego-Aranda M, Hernández-Becerril N, GarzaMurillo Cardenas VM, Reyes PA, Hirayama K, Monteón VM 2003. Electrocardiographic findings in Mexican subjects living in high and low endemic regions of Trypanosoma cruzi infection. Mem Inst Oswaldo Cruz 98: 605-610.

Souto RP, Fernandes O, Macedo AM, Cambell DA, Zingales B 1996. DNA markers define two major phylogenetic lineages of Trypanosoma cruzi. Mol Biochem Parasitol 83: 141-152.
Umezawa ES, Bastos S, Camargo ME, Yamauchi LM, Santos MR, Gonzalez Zingales B, Levin MJ, Sousa O, Rangel-Aldao R, da Silveira JF 1999. Evaluation of recombinant antigens for serodiagnosis of Chagas' disease in South and Central America. J Clin Microbiol 37: 1554-1560.

Umezawa ES, Luquetti AO, Levitus G, Ponce C, Ponce E, HenriquezRevollo DS, Espinoza B, Sousa O, Khan B, da Silva JF 2004. Serodiagnosis of chronic and acute Chagas' disease with Trypanosoma cruzi recombinant proteins: result of a collaborative study in six latin America countries. J Clin Microbiol 42: 449-452. 